\title{
The "Need for Harmony" Defence Mechanisms as Co-Factor in Stress Sensitivity Producing Sadness and Depression
}

\author{
Valeria Biasi' ${ }^{1}$, Paolo Bonaiuto \\ ${ }^{1}$ Department of Education, "Roma Tre" University, Rome, Italy \\ 2Department of Psychology, "Sapienza" University of Rome, Rome, Italy \\ Email: valeria.biasi@romascuola.net, paolo.bonaiuto@uniroma1.it
}

Received 1 September 2014; revised 3 October 2014; accepted 5 November 2014

Copyright (C) 2014 by authors and Scientific Research Publishing Inc.

This work is licensed under the Creative Commons Attribution International License (CC BY). http://creativecommons.org/licenses/by/4.0/

\section{(c) (i) Open Access}

\section{Abstract}

The aim of this investigation is to develop useful research toolsfor assessingpsychological traits and defence mechanisms towardnegative emotions. The present study examined 124 young women adults (19 - 39 years) participating in short-term stress sessions conducted with a noninvasive procedure called "Drawing Recollection" of real personal stressful life experiences (Biasi \& Bonaiuto, 1997a, 1997b, 2007). This treatment lasts 20 minutes and is as effective as the heavier traditional techniques. Emotional and motivational changes are documented by pre- and posttreatment bipolar "Self-Appraisal Scales" (Biasi, Bonaiuto, \& Giannini, 2010). With the LDM Inventory, the participants were selected and divided into two contrasting extreme groups, according to their very high or very low Need for Harmony $(\mathrm{N} / \mathrm{H})$ sub-scale scores. We identified favourable and unfavourable personality traits for developing specific negative emotions under stress: in particular the $\mathrm{N} / \mathrm{H}$, concerning the tendency to avoid interpersonal conflicts at the cost of selfsacrifice and self-punishment (Spielberger, 1988; Spielberger \& Reheiser, 2000). Participants who obtained high "Sadness" scores under stress (measured by "Self-Appraisal Scales"), had significantly higher scores on $\mathrm{N} / \mathrm{H}$ scales compared to the opposite group $(p<0.001)$. The $\mathrm{N} / \mathrm{H}$ defence mechanism and negative emotion of "Sadness" ("Depression") combination represents significant co-factors of stress sensitivity.

\section{Keywords}

Defence Mechanism, Depression, Need for Harmony, Personality, Stress Sensitivity 


\section{Introduction}

Recent clinical studies conducted by Spielberger \& Sarason (2005) and Spielberger \& Reheiser (2009) show that anxiety, anger and depression are important indicators of psychological distress and require careful assessment. Of particular interest is the relations of these negative emotions with so-called "curiosity"; as a state condition this means the "intensity of feelings and cognitions relating to curiosity and interest in exploratory behavior at a particular time"; and as a trait condition it "measures how often feelings of curiosity, inquisitiveness and interest in exploring the environment are experienced over time" (Spielberger \& Reheiser, 2009: p. 292). The assessment of these emotional states (anxiety, anger, depression) and the attitude of curiosity are examined especially by Spielberger \& Reheiser (2009) also through the construction and development of the State-Trait Anxiety Inventory (STAI), the State-Trait Anger Expression Inventory (STAXI-2), and the State-Trait Personality Inventory (STPI). Findings demonstrated the efficacy of these measures in research and clinical practice.

In line with this theoretical approach we present an investigation based on experimental techniques suitable for producing short-term stress situations with adult participants.

The most frequent emotional effects, measured with various procedures, generally consist of increasing the so-called "negative" emotions, such as anxiety, anger and sadness, but also suffering, embarrassment, guilt, shame, feelings of inferiority, insecurity and insufficiency (Bonaiuto, Biasi, Giannini, Bonaiuto, \& Bartoli, 1992; Biasi \& Bonaiuto, 1997a, 1997b, 2007). Moreover, in our previous experiments we demonstrated that, in these experimental conditions, even some motivational systems are activated, such as aggression, the need for cognitive congruence and the need for active body movement. These lead to further "cascade" effects, among which the activation of psychological defense mechanisms, whose specificity reveals the individually consolidated affective habits as well as some underlying personality structures.

This experimental short term stress paradigm allows the diagnosis of behavioral predispositions and the formulation of clinical predictions (Freud, 1936; Perry, 1990; Cramer, 1991; Vaillant, 1992; Lingiardi \& Madeddu; 1994; Bartoli \& Bonaiuto, 1997). Finally, the experimental study of short-term stress allows us to identify which defense mechanisms are adopted with respect to the individual personological profile. In particular, this investigation aims to detect the intervention of a specific defence mechanism called "Need for Harmony" inpersonalities that are extremely sensitive in coping with stress, in conditions of psychological conflict overload. This high level of stress sensitivity is demonstrated by the fact that they produce an intolerable level of negative emotions, specifically sadness and depression.

\section{Relevant International Investigations on Lifestyle Defence Mechanisms, and the Study of Psychosomatic Components of Diseases}

Spielberger (1988), and Spielberger and Reheiser (2000) in the United States, and then applied, also with other collaborators, in some European Countries. In Italy the work of translation and local adaptation has been performed by us in cooperation with the University of Padua, as detailed in some research reports (Comunian, Biasi, Giannini, \& Bonaiuto, 2001, 2003, 2004). This work has led to an exploratory factor analysis, the replacement and improvement of some items from the original composition of the LDM Inventory, maintaining the same total number (24 items). Then a confirmatory factor analysis was carried out, plus a control of the meaning equivalences with bilingual participants, experts in both languages, Italian and English.

The LDM Inventory consists of two separate scales, each containing two subscales. The first scale, named "Need for Harmony" (NH), includes twelve items and is on turn divided into two subscales: "Self-Sacrifice" (SS) and "Harmonious Relations" (HR). According to the original construct, which was derived from the pionier studies of Grossarth-Maticeck (1980), these components are focused on the efforts to achieve and mantain harmonious relationships with family and friends.

The second scale, named "Rationality/Emotional Defensiveness" (R/ED) includes other twelve items and is the sum of two subscales: "Rationality" (RAT) and "Emotional Defensiveness" (EmD). These components are focused on the frequency that a person engages in rational, anti-emotional thought processes and behaviors (Spielberger, 1988; Spielberger \& Reheiser, 2000. See also Fernandez-Ballesteros, Zamarron, Ruiz, Sebastian, \& Spielberger, 1997). We will see how our study will partially confirm and enrich previous findings by some experimental, personological and clinical operators, from Grossarth-Maticek (1980), and Grossarth-Maticek (1990) to Eysenck (1994), to Temoshok and Dreher (1992), to Fernandez-Ballesteros et al. (1997), and to several others. 
Spielberger and Reheiser (2000) reported three studies (doctoral dissertations) held respectively by Kresner (1989) and Hann (1993), who using the R/ED scale, examined women with breast cancer ( $=155)$ and women with benign breast tumours $(n=104)$, at clinical and research Institutions of the University of South Florida. The results of factors analyses showed that the operation of the defence mechanism of repression and denial in cancer patients may inhibit them from experiencing and expressing angry feelings.

Also reported is a study by Swan et al. (1991) who examined among other patients 157 men and 164 women that had been previously diagnosed with some form of cancer (other than skin cancer). The males who had been diagnosed with cancer had higher R/ED Scales scores than males without cancer.

The relation was reversed in women, in contrast with the hypothesis and with the results of the previous studies: women diagnosed with cancer had somewhat lower R/ED Scales scores than women without cancer.

According to Spielberger and Reheiser, the failure to found the expected relations might be due to the advanced age of the participants in the Swan et al. study (1992), and to the fact that they were also cancer survivors.

Spielberger has advanced the theoretical and empirical foundations of professional psychology through his research on personality and learning; stress and emotion; assessment of anxiety, anger, and curiosity; and lifestyle factors that influence the etiology of hypertension, cardiovascular disorders, and cancer.

Comunian, Biasi, Giannini and Bonaiuto (2004) examined the reliability and validity of scores from the Italian adaptation of Lifestyle Defense Mechanisms Inventory (LMD) (Spielberger, 1988; Spielberger \& Reheiser, 2000), administered to a sample of 502 undergraduate Italian students. The internal reliability of the Italian LDM Inventory was comparable to that from samples using the English LDM Inventory (range: .89 to .94) suggesting that items from Italian instrument are addressing a unitary construct in this sample. They performed a Confirmatory Factor Analysis of a previously reported 2-factor solution for the Italian LDM Inventory subscales derived from different Italian samples (Comunian, Biasi, Giannini, \& Bonaiuto, 2001, 2003).

Results indicate that the established model for the Italian-speaking sample provided adequate fit in the present sample. Moreover, Italian LDM Inventory scores were significantly associated with gender. Bilingual participants completed the inventory in both Italian and English, and their data revealed that LDM total subscale scores were similar across language administration. Our results provide the first data addressing the equivalence of Italian LDM Inventory and English LDM Inventory scores. We found that bilingual participants' Italian and English LDM Inventory scores were not significantly different from one another.

\section{The Present Study}

\subsection{Hypothesis}

The investigation aimed to develop useful research tools for assessing psychological traits and differentiate attitudes toward negative emotions. These attitudes may constitute interesting personological features as well as, in some cases, specific risk factors for psychosomatic components of specific diseases.

On the basis of general knowledge in this field, we can say that personal conditions of poor tolerance of psychological conflict, combined with inhibitions of aggressiveness, particularly favour the increase of one of the negative emotions: sadness. This is because it is an emotion which is more compatible with the described dynamic configuration, i.e. with the economy of one's own affective balance in the given conditions. Taking into account this psychological dynamic, we proposed to examine young adults characterised by a high "Need for Harmony", as a Lifestyle component, according to the definition of Spielberger \& Reheiser (2000). This trait includes aspects of open conflict avoidance (especially interpersonal conflicts) and a self-sacrificing tendency (in order to benefit others in a real or presumed manner). Following increases in conflict, these predispositions lead one to prefer self-punishing solutions instead of open expressions of anger and aggressiveness. We can also speculate that the above-mentioned personality type involves a constellation of traits which can be documented with further instruments: particularly, a positive correlation with other defence components, such as so-called rationality and anti-emotionality, the evaluations of which are also available by using the LDM Inventory.

In order to test this hypothesis, we examined people with high scores in "Need for Harmony", always described as the defensive inclination to achieve and maintain harmonious relations with family, friends and other persons, and preventing or reducing interpersonal conflicts even at the cost of self-sacrifice. We advance the hypotheses that these extreme subjects develop the emotion of sadness very intensely under stress. 


\subsection{Method, Procedure and Participants}

As the technique for inducing short term experimental stress we used an efficacious but non-invasive procedure: the recollection and drawing of real personal stressfull experiences (twenty minutes). The comparison was made with short term experimental comfort treatment, in which the participants recall and draw real personal comfort experiences (Biasi \& Bonaiuto, 2007). Changes in affective states were evaluated applying seven point bipolar Self-Appraisal Scales before each treatment and at its apex. Analyses of the obtained pre-treatment scores demonstrated that the above mentioned extreme subjects were significantly higher in positive emotions (such as happiness, serenity, distension) with respect to those lower in "Need for Harmony"; while after the stress treatment a dramatic inversion occurred, especially with the development of sadness. This was interpreted as a consequence of the typical tendency of such persons to re-direct aggressiveness, developed under stress, toward the self, preventing interpersonal conflict.

In order to induce short-term experimental stress, we used an efficacious but non-invasive technique: the recollection and drawing of real personal stressful experiences (twenty minutes). The comparison was made with a short-term experimental comfort treatment, in which the participants recall and draw real personal comfort experiences (Biasi \& Bonaiuto, 2007). Changes in affective states were evaluated by means of seven-point bipolar Self-Appraisal Scales before each treatment and at its apex. Analyses of the obtained pre-treatment scores demonstrated that the above-mentioned extreme subjects were significantly higher in positive emotions (such as happiness, serenity, distension) with respect to those lower in "Need for Harmony"; while after the stress treatment a dramatic inversion occurred, especially with the development of sadness. This was interpreted as a consequence of the typical tendency of such persons to re-direct aggressiveness, developed under stress, toward the self, preventing interpersonal conflict.

In order to have suitable experimental demonstrations, we previously examined 124 young women adults (aged 19 - 39 years) using the Lifestyle Defense Mechanisms (LDM) Inventory (by Spielberger \& Reheiser, 2000). As is known, this tool includes two 12-item self-report scales: "Rationality/Emotional Defensiveness" and "Need for Harmony". These can provide reliable evaluations on the so-called base levels of defence mechanisms, and may also envisage appropriate sub-scales.

The above-mentioned participants were submitted to a special condition of short-term experimental stress, lasting 20 minutes. Among the available procedures we gave our preference to a technique we have used extensively in recent years, and that we call "drawn recollection of previous real-life personal stressful experiences" (Biasi \& Bonaiuto, 1997a, 1997b, 2007). According to our experimental setting, the subject sits at a well-lit table and is provided with light pieces of drawing cardboard $(32 \times 24 \mathrm{~cm})$, a black pencil, an eraser, a black pen, thirty-six coloured pastels and thirty-six coloured felt-tip pens. Each person is asked to represent her/his own stressful or relaxing real-life experiences. Every drawing session lasts 20 minutes. If there is enough time, the participant is asked to recollect and represent another situation of the same type. Usually, each person is examined individually. Nevertheless, for this last experiment, in order to save time and energy, we used a group procedure that proved to be effective in other similar conditions. Participants, in any case, worked individually, sitting apart from each other, in groups of 30 people, each subject having the prescribed materials. Instead of individual oral instructions, for this experiment, we prepared and applied written instructions, with the same content. The written instructions, given to each subject, were as follows: "Now try to imagine and focus on a personal, particularly stressful, anxiety arousing, troubling and unpleasant situation. It can be a past experience or a present one that you have felt in this way. Try to represent this experience with the materials here at your disposal. Do it freely, as you are able to, using whatever you wish...” These instructions are always well understood and people usually produce some very interesting drawings. One of the main recollected and illustrated topics is congested urban traffic (which, in Rome, is very heavy and well known). People also draw car accidents, family arguments, school examinations, feelings of isolation, illness or death of relatives. Sometimes they represent stress in symbolic or abstract ways: black sun, stains, blots, straight and interrupted segments, etc. We have observed that, in spite of the materials at their disposal, subjects mostly use only black and white to represent their stressful experiences. The psychological effects - on emotions, motivations, and other processesof the above-mentioned experimental drawing procedures are quite remarkable. Despite the fact that this is a non-intrusive procedure, all the same it is able to induce very effective short-term (reversible) states of stress. Achievement of the programmed emotional states and the intensity of the main activated emotions, motivations and impressions are checked by means of pre-post treatment Self-Appraisal Scales. These are seven-point scales 
including several items (Figure 1; Bonaiuto, Biasi, Giannini, Bonaiuto, \& Bartoli, 1992; Biasi, Bonaiuto, \& Giannini, 2010).

We must again note that the recorded influences upon affective, cognitive and decisional processes turned out to be very similar to those we observed with classical more demanding and invasive techniques for inducing stress.

Factor analyses showed that, on the basis of main component analysis of the scores obtained at peak stress, some emotional factors were found, such as "Anxiety", "Anger" and "Sadness", each of which grouped together four relevant items, with saturations ranging from 0.50 to 0.95 (Table 1). The values of between-factor correlations (from 0.55 to 0.49 ) supported the discriminative validity, also enabling a grouping within the super-ordinate factor "Negative Emotions".

As regards motivations, changes after stress treatment showed increases in Aggression, Need for Body Movement and Need for Orderly Knowledge. Each of these three motivations grouped together three relevant items with saturations ranging from 0.50 to about 0.90 (Table 2).

From the above-mentioned population of 124 participants, we selected two contrasting extreme groups on the basis of the Need for Harmony scores. The average score in this population was 32.97 points, with a standard deviation of 5.72 points (Table 3). By adding or subtracting the value of one standard deviation to or from the mean, we obtained the possibility of distinguishing:

a) Participants with a Very High Level of Need for Harmony, having a score equal to or above 39 points. Number: 20 subjects.

b) Participants with a Very Low Level of Need for Harmony, having a score equal to or above 27 points. Number: 20 subjects.

\subsection{Results}

We recorded a series of interesting results obtained by applying the Self-Appraisal Scales before and after stress

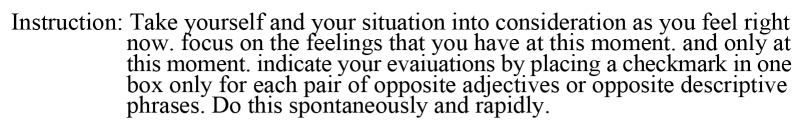

I feel I am

\begin{tabular}{l|l|l|l|l|l|l|l|l}
\multicolumn{2}{c}{3} & 2 & 1 & 0 & 1 & 2 & 3 \\
\hline TENSE & & & & & & & & RELAXED \\
\hline AGITATED & & & & & & & & CALM \\
\hline $\begin{array}{l}\text { IN CONFLICT } \\
\text { INTERNALLY }\end{array}$ & & & & & & & & $\begin{array}{l}\text { AT PEACE } \\
\text { INTERNALLY }\end{array}$ \\
\hline WORRIED & & & & & & & & TRANQUIL \\
\hline ANGRY & & & & & & & & SERENE \\
\hline IRRITATED & & & & & & & & AGREEABLE \\
\hline AGGRESSIVE & & & & & & & & PEACEFUL \\
\hline IMPATIENT & & & & & & & & PATIENT \\
\hline SAD & & & & & & & & HAPPY \\
\hline EMBITTERED & & & & & & & & $\begin{array}{l}\text { WELL- } \\
\text { DISPOSED }\end{array}$ \\
\hline DEPRESSED & & & & & & & & EUPHORIC \\
\hline MELANCHOLIC & & & & & & & & JOYFUL \\
\hline
\end{tabular}

Figure 1. Some items of the "Self-Appraisal Scales". 
Table 1. Main component analysis with Obliminrotation, carried out on the SelfAppraisal Scales administered at the peak of stress treatment on 144 adults of both genders (Biasi, Bonaiuto, \& Giannini, 2010).

\begin{tabular}{cccc}
\hline \multirow{2}{*}{ Items } & \multicolumn{3}{c}{ Factors } \\
\cline { 2 - 4 } Tense & Anxiety & Anger & Sadness \\
Nervous &. $\mathbf{8 8}$ & .04 & .12 \\
In conflict & .74 & .01 & -.05 \\
Worried &. $\mathbf{6 8}$ & -.09 & -.13 \\
Aggressive & .50 & .21 & -.21 \\
Angry & $\mathrm{v} .01$ &. $\mathbf{8 3}$ & -.17 \\
Impatient & .24 & $\mathbf{. 6 6}$ & -.02 \\
Irritated & -.09 & .93 & .06 \\
Depressed & .28 & .59 & -.11 \\
Sad & -.04 & -.09 & -.95 \\
Melancholic & -.05 & .12 &.$- \mathbf{8 7}$ \\
Embittered & .03 & .08 &.$- \mathbf{8 1}$ \\
\hline
\end{tabular}

Table 2. Main component analysis with Oblimin rotation, using the Orthotran/Varimax method, carried out on the Self-Appraisal Scales administered at the peak of stress treatment on 144 adults of both genders (Biasi, Bonaiuto, \& Giannini, 2010).

\begin{tabular}{cccc}
\hline \multirow{2}{*}{ Items } & \multicolumn{3}{c}{ Factors } \\
\cline { 2 - 4 } & Aggression & Orderly Knowledge & Body Movement \\
\cline { 2 - 4 } Teasing someone &. $\mathbf{7 9}$ & -.01 & -.02 \\
Being able to breack objects &. $\mathbf{6 3}$ & .00 & .05 \\
Being able to hit someone & $\mathbf{. 5 9}$ & -.02 & -.04 \\
Need for making order & -.01 & $\mathbf{. 8 6}$ & -.05 \\
Feeling connections between things & .09 & $\mathbf{. 8 6}$ & .05 \\
Wanting effective explanations & -.05 & $\mathbf{. 6 2}$ & .05 \\
Acting quickly and effectively & .01 & .03 & $\mathbf{. 8 7}$ \\
Moving energetically & -.08 & -.03 & $\mathbf{. 7 7}$ \\
Doing one's favourite sport & -.04 & -.09 & -.95 \\
\hline
\end{tabular}

Table 3. Mean scores and Standard Deviation, in brackets, of selected two contrasting extreme groups on the basis of the "Need for Harmony" scores.

\begin{tabular}{ccc}
\hline & Mean Scores and Standard Deviation & Selected Score Ranges \\
\hline All Participants & 32.97 & 1 Standard Deviation above or below the Mean \\
$(\mathrm{N}=124)$ & $(5.72)$ & \\
Participants with Very High Need for & 40.75 & 1 Standard Deviation equal or superior to 39 points \\
Harmony ( $=20)$ & $(1.80)$ & \\
Participants with Very Low for Need & 24.75 & 1 Standard Deviation equal or inferior to 27 points \\
for Harmony $(\mathrm{n}=20)$ & $(2.87)$ & \\
\hline
\end{tabular}


treatment. The results show the typical average effects of stress conditions on emotional and motivational makeup in the above-mentioned two contrasting groups.

a) People with a very high Need for Harmony also have significant scores of Rationality and Emotional Defensiveness. The correlation between the two traits, considering, of course, the overall population of 124 participants (and not only the extreme groups), reaches $0.40(p<.001)$. This is in agreement with the usual results when using the LDM Inventory, in various countries.

Other peculiarities of these persons may be found by considering the basic emotional levels evaluated with the Self-Appraisal Scales. The latter tool allows us to discover that, before experimental treatment (Figure 2), that is, at the baseline level, people with a very high Need for Harmony, compared to those with a very low Need for Harmony, are characterised by higher scores of self-reported happiness, which is the opposite emotion to sadness. The same people exhibit higher scores for self-reported serenity, as the opposite emotion to anger.

Although these people are known to be quite problematic, they avoid considering themselves as bearers of internal conflicts and of the resulting negative emotions. They prefer a self-image which may be described as happy and serene. This confirms their tendency to use defence mechanisms such as repression and denial.

b) When submitted to the short-term stress treatment, people with a very high Need for Harmony $(n=20)$, compared to people with a very low Need for Harmony $(n=20)$, are characterised by the development of significantly higher levels of three main negative emotions as anxiety, anger and sadness (Figure 3), but if we analyse the specific data, we discover that increases in anger and anxiety that are seen do not statistically differ from those found in subjects of the opposite type (Figure 4).

The main specific effect is centered on the increase in "sadness" under stress conditions (Figure 5): A typical negative emotion linked to the personality profile of participants with very high Need for Harmony levels. This emotion clearly increases in subjects of the first type, while it remains stable in subjects of the opposite type ( $\mathrm{t}$ $38=3.99 ; p<.001)$.

The effect found confirms the hypothesis and is interpreted as a main result of the increase in psychological conflict in stressful conditions, accompanied by the repression of the resulting hetero-aggressiveness and the channeling towards the self of pervasive aggressive need that would not otherwise be met.

We thus confirm that the development of negative emotions under stress is not generic, but is governed by constraints and affective habits already present in the personality: among which, in this case, the typical Lifestyle Defence Mechanism called "Need for Harmony". We confirm that the "Need for Harmony", with its aspects of the tendency to avoid interpersonal conflicts at the cost of self-sacrifice and self-punishment, is a significantly predictive trait for the particular increase of sadness under stress.

This study confirms that people with very high levels of Need for Harmony are even more dependent on other

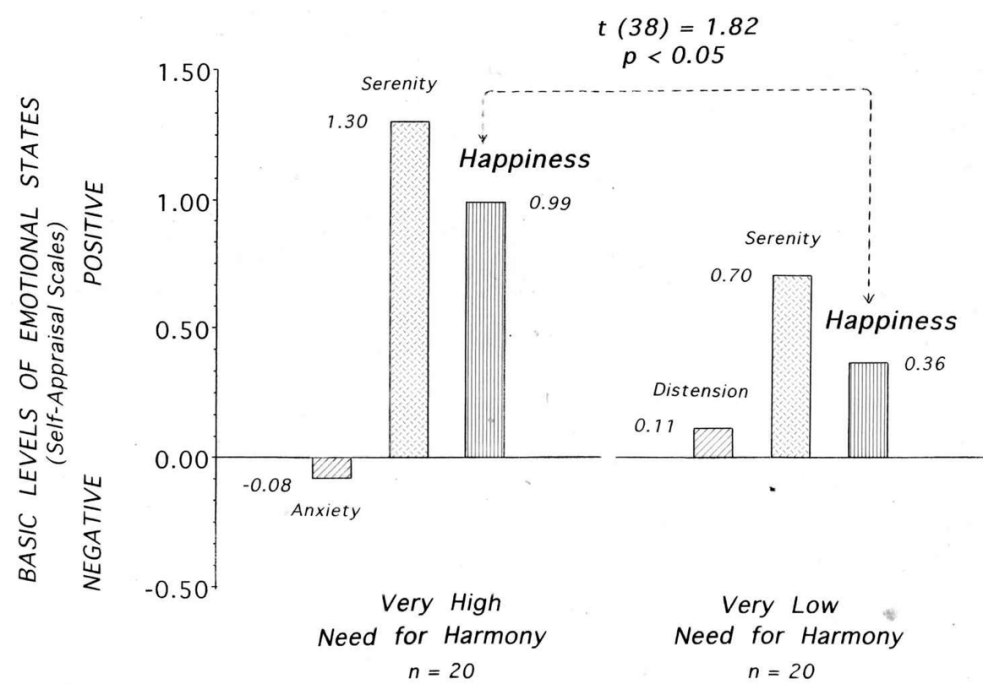

Figure 2. The basic level emotional states of the very high Need for Harmony participants, before the experimental treatment, compared to the very low Need for Harmony subjects, are characterised by higher scores of self-reported Hap piness and Serenity. 


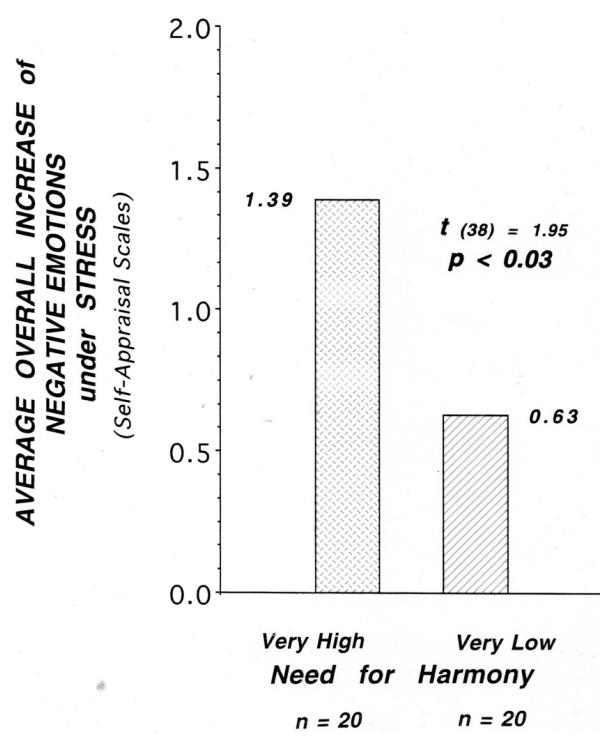

Figure 3. Average Scores of three Negative Emotions (Anxiety, Anger and Sadness) obtained under stress treatment by Participants with Very High Need for Harmony Levels versus Participants with Very Low Need for Harmony Levels.

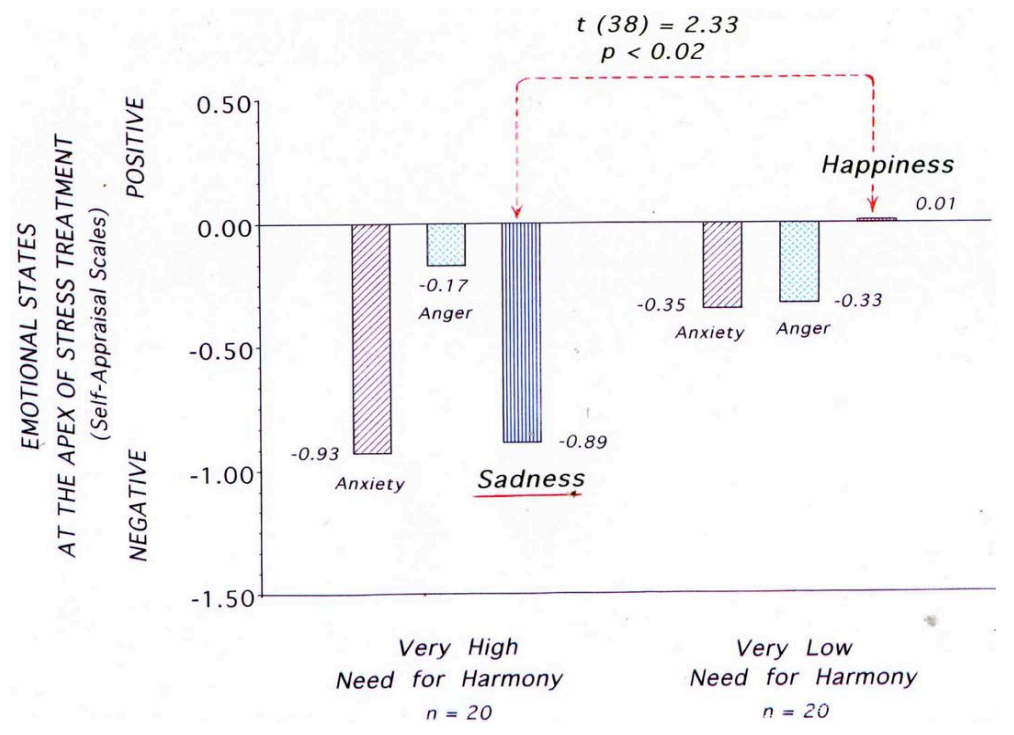

Figure 4. Emotional states at the apex of stress treatment of Very High Need for Harmony participants, with respect to Very Low Need for Harmony ones, are characterized by higher scores of self-reported Anxiety and Sadness.

people, avoiding interpersonal overt conflict and some emotional reactions to stress, such as anger and aggression, that may directly complicate interpersonal relationships.

\section{Discussion and Conclusions}

In conclusion, the collected data show that when submitted to a short-term stress treatment, people with a Very High Need for Harmony, compared to those with a Very Low Need for Harmony, are characterised by the development of significantly higher levels of negative emotions and particularly sadness. This emotion clearly in- 


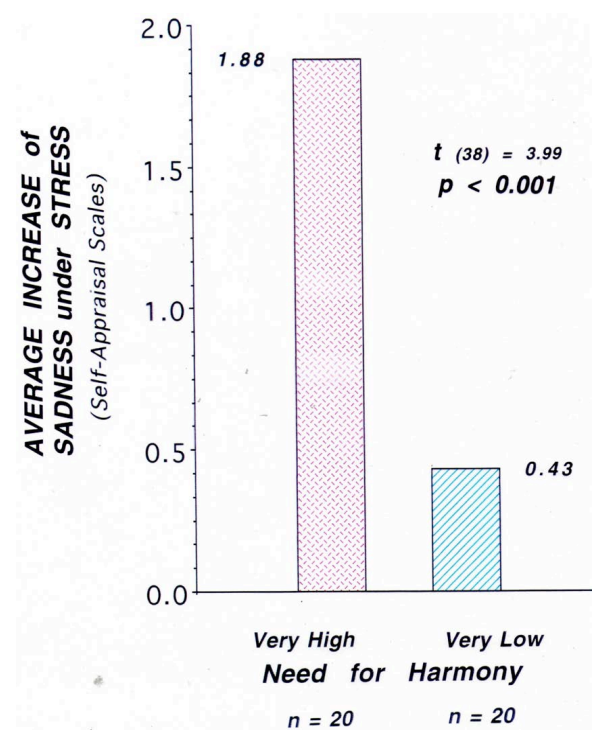

Figure 5. Average Scores of Sadness obtained under stress treatment by Participants with Very High Need for Harmony Levels versus Participants with Very Low Need for Harmony Levels.

creases in subjects of the first type, while it remains stable in subjects of the opposite type. Increases in anger and anxiety appear not to differ, though, in subjects of the opposite type.

The effect we found confirms the hypothesis and is interpreted as a main result of the increase in psychological conflict in stressful conditions, accompanied by the repression of the resulting hetero-aggressiveness and the channeling towards the self of pervasive aggressive need that would not otherwise be met. This interpretation is in line with the fact that a high degree of Need for Harmony tends to accompany a high degree of self-punishment (“Anger-in", according to the STAXI); together with other indicators for controlling and inhibiting anger. We thus confirm that the development of negative emotions under stress is not generic, but is governed by constraints and affective habits already present in the personality: among which, in this case, the typical Lifestyle Defence Mechanism called "Need for Harmony". We confirm that the "Need for Harmony", with its aspects of the tendency to avoid interpersonal conflicts at the cost of self-sacrifice and self-punishment, is a significantly predictive trait for the particular increase of sadness under stress.

Our finding confirms and enriches the previous findings by some operators, from Grossarth-Maticek and his collaborators (1980), to Fernandez-Ballesteros and collaborators (1997). Generally, people with the highest "Need for Harmony" scores have the highest tendency to be empathetic, in the sense of taking care of the wishes of others, to have acquiescent behaviors, and, finally, to avoid interpersonal conflicts.

Confirmation of these relations in a different population, as the Italian one, contributes to broadening the empirical basis in favour of the theory that personological features may significantly interfere with the natural mechanisms of health. Of course, it is necessary to go deeper into these problems with more data on different populations and also with prospective studies centered on psycho-physiological mechanisms and components.

The experimental investigation presented allowed us to identify favourable and unfavourable personality traits for developing negative emotions under stress. In particular, the "Need for Harmony", with the tendency to avoid interpersonal conflicts at the cost of self-sacrifice and self-punishment (Spielberger, 1988), turned out to be a useful predictive trait in the aforesaid sense. The investigation also allowed us to assess the effects of psychological conflict overload as co-factors of stress sensitivity.

This relevant trait, leading to prevent or reduce interpersonal conflicts, even at the cost of self-sacrifice, and to prefer denial and repression of negative emotions, appears as a significant risk factor also for tumoural pathologies as detected in different international investigations. The effect we found can be interpreted as a main result of the increase in psychological conflict in stressful conditions, accompanied by the repression of the resulting hetero-aggressiveness and the channeling towards the self of pervasive aggressive need that would not otherwise 
be met. This interpretation is also in line with the fact that a high degree of Need for Harmony tends to accompany a high degree of self-punishment (“Anger-in”, according to the STAXI by Spielberger). In a sample of 64 participants we calculated the correlation with Need for Harmony and the "Anger-in" scores as $r_{62}=0.29$, $p<.03$.

This study confirms that people with very high levels of Need for Harmony are even more dependent on other people, and avoid interpersonal overt conflict and some emotional reactions to stress, such as anger and aggression, that may directly complicate interpersonal relationships. At a profound level, with clinical interviews, patients with very high levels of Need for Harmony were found to be particularly afraid of abandonment and to be particularly insecure in their relational style for this fear. The data thus show that the development of negative emotions under stress is not generic, but is governed by constraints and affective habits already present in the personality: among which, in this case, the typical Lifestyle Defence Mechanism called "Need for Harmony". We confirm that the tendency to avoid interpersonal conflicts at the cost of self-sacrifice and self-punishment, is a significantly predictive trait for the particular increase of sadness and depression under stress.

\section{References}

Bartoli, G., \& Bonaiuto, P. (1997). Psicodinamica e sperimentazione. Rome: Nuova Italia Scientifica.

Biasi, V., \& Bonaiuto, P. (1997a). Colour and the Experimental Representation of Stress and Comfort. In L. Sivik (Ed.), Colour \& Psychology (pp. 54-65). Stockholm: Scandinavian Colour Institute.

Biasi, V., \& Bonaiuto, P. (1997b). Aesthetic Level of Drawings Made under Conditions of Emotional Activation. In L. Dorfman, C. Martindale, D. Leontiev, G. Cupchik, V. Petrov, \& P. Machotka (Eds.), Emotion, Creativity and Art (pp. 319-348). Perm: Perm State Institute of Arts \& Culture.

Biasi, V., \& Bonaiuto, P. (2007). Stress or Comfort Drawings. A Technique for Activating and Evaluating Real Emotional States and for Detecting Emotional Meanings. In V. L. Zammuner, \& C. Galli (Eds.), Giornata di Studio sulle Emozioni, Proceedings (pp. 66-69). Padua: CLEUP.

Biasi, V., Bonaiuto, P., \& Giannini, A. M. (2010). Measures of Emotional and Motivational Processes Activated by Stress or Comfort Conditions. Key Engineering Materials, 437, 540-544. http://dx.doi.org/10.4028/www.scientific.net/KEM.437.540

Bonaiuto, P., Biasi, V., Giannini, A. M., Bonaiuto, M., \& Bartoli, G. (1992). Stress, Comfort and Self-Appraisal: A Panoramic Investigation of the Dynamics of Cognitive Processes. In D. G. Forgays, T. Sosnowski, \& K. Wrzesniewski (Eds.), Anxiety: Recent Developments in Cognitive, Psychophysiological and Health Research (pp. 75-107). Washington DC: Hemisphere.

Comunian, A. L., Biasi, V., Giannini, A. M., \& Bonaiuto, P. (2001). Lifestyle Defense Mechanism Inventory Preliminary Italian Adaptation Study. Abstract in J. Pèrez-Pareia, A. Sezè, \& C. Borràs (Eds.), 22nd International Conference STAR. Book of Abstracts (p. 48). Palma de Mallorca: Balearic Islands University/Formularios y Papel Continuo.

Comunian, A. L., Biasi, V., Giannini, A. M., \& Bonaiuto, P. (2003). The Validity and Reliability of the Lifestyle Defense Mechanisms Inventory in Italy. Abstract in A. Baptista (Ed.), 24th International Conference Stress and Anxiety. Book of Abstracts (p. 51). Lisboa: Universidade Lusòfona de Umanidades e Tecnologias.

Comunian, A. L., Biasi, V., Giannini, A. M., \& Bonaiuto, P. (2004). Psychometric Properties of the Italian Lifestyle Defense Mechanisms Inventory. Abstract in J. Meijer, \& R. Oostdam (Eds.), 25th Stress and Anxiety Research Society Conference. Book of Abstracts (p. 63). Amsterdam: SCO-Kohnstamm Instituut.

Cramer, P. (1991). The Development of Defense Mechanisms: Theory, Research, and Assessment. New York: SpringerVerlag. http://dx.doi.org/10.1007/978-1-4613-9025-1

Eysenck, H. J. (1994). Cancer Personality and Stress: Prediction and Prevention. Advances of Behavioral Research and Therapy, 16, 167-215. http://dx.doi.org/10.1016/0146-6402(94)00001-8

Fernandez-Ballesteros, R., Zamarron, M. D., Ruiz, M. A., Sebastian, J., \& Spielberger, C. D. (1997). Assessing Emotional Expression: Spanish Adaptation of the Rationality/Emotional Defensiveness Scale. Personality and Individual Differences, 22, 719-729. http://dx.doi.org/10.1016/S0191-8869(96)00250-4

Freud, A. (1936). Das Ich und die Abwehrmecanismen. Wien: Verlag.

Grossarth-Maticek, R. (1980). Psychosocial Predictors of Cancer and Internal Diseases: An Overview. Psychotherapy \& Psychosomatics, 33, 122-128. http://dx.doi.org/10.1159/000287422

Grossarth-Maticek, R., \& Eysenck, H. J. (1990). Personality, Stress and Disease: Description and Validation of a New Inventory. Psychological Reports, 66, 355-373. http://dx.doi.org/10.2466/pr0.1990.66.2.355

Hann, D. M. (1993). Personality and Lifestyle Diagnosis of Breast Cancer Patients. Unpublished Doctoral Dissertation, 
Tampa, FL: University of South Florida.

Kresner, S. S. (1989). Psychosocial Correlates of Progression in Breast Cancer. Unpublished Doctoral Dissertation, Tampa, FL: University of South Florida.

Lingiardi, V., \& Madeddu, F. (1994). I meccanismi di difesa. Teoriaclinica e ricercaempirica. Milano: Cortina.

Spielberger, C. D. (1988). The Rationality/Emotional Defensiveness (R/ED) Scale. Preliminary Test Manual, Tampa, FL: Center for Research in Behavioral Medicine and Health Psychology, University of South Florida.

Spielberger, C. D., \& Reheiser, E. C. (2000). Lifestyle Defense Mechanisms Inventory. Tampa, FL: Center for Research in Behavioral Medicine and Health Psychology, University of South Florida.

Spielberger, C. D., \& Reheiser, E. C. (2009). Assessment of Emotions: Anxiety, Anger, Depression, and Curiosity. Applied Psychology: Health and Well-Being, 1, 271-302.

Spielberger, C. D., \& Sarason, I. G. Eds. (2005). Stress and Emotion: Anxiety, Anger, and Curiosity (Volume 17). New York: Hemisphere/Taylor \& Francis.

Swan, G. E., Carmelli, D., Dame, A., Rosenman, R. H., \& Spielberger, C. D. (1991). The Rationality/Emotional Defensiveness Scale-I. Internal Structure and Stability. Journal of Psychosomatic Research, 35, 545-554. http://dx.doi.org/10.1016/0022-3999(91)90049-T

Swan, G. E., Carmelli, D., Dame, A., Rosenman, R. H., \& Spielberger, C. D. (1992). The Rationality: Emotional Defensiveness Scale-II. Convergent and Discriminant Correlational Analysis in Males and Females with and without Cancer. Journal of Psychosomatic Research, 36, 349-359. http://dx.doi.org/10.1016/0022-3999(92)90071-9

Temoshok, L., \& Dreher, A. W. (1992). The Type C Connection. New York: Random House.

Vaillant, G. E. (1992). Ego Mechanisms of Defense. Washington DC: American Psychiatric Press. 
Scientific Research Publishing (SCIRP) is one of the largest Open Access journal publishers. It is currently publishing more than 200 open access, online, peer-reviewed journals covering a wide range of academic disciplines. SCIRP serves the worldwide academic communities and contributes to the progress and application of science with its publication.

Other selected journals from SCIRP are listed as below. Submit your manuscript to us via either submit@scirp.org or Online Submission Portal.
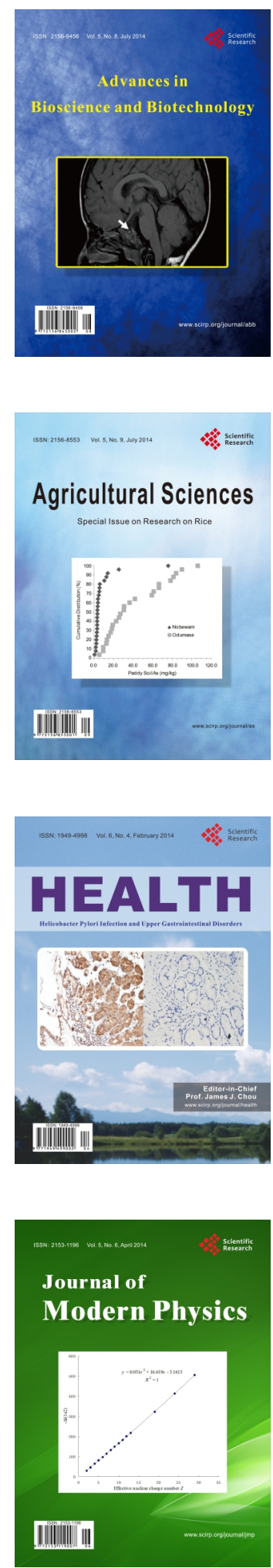
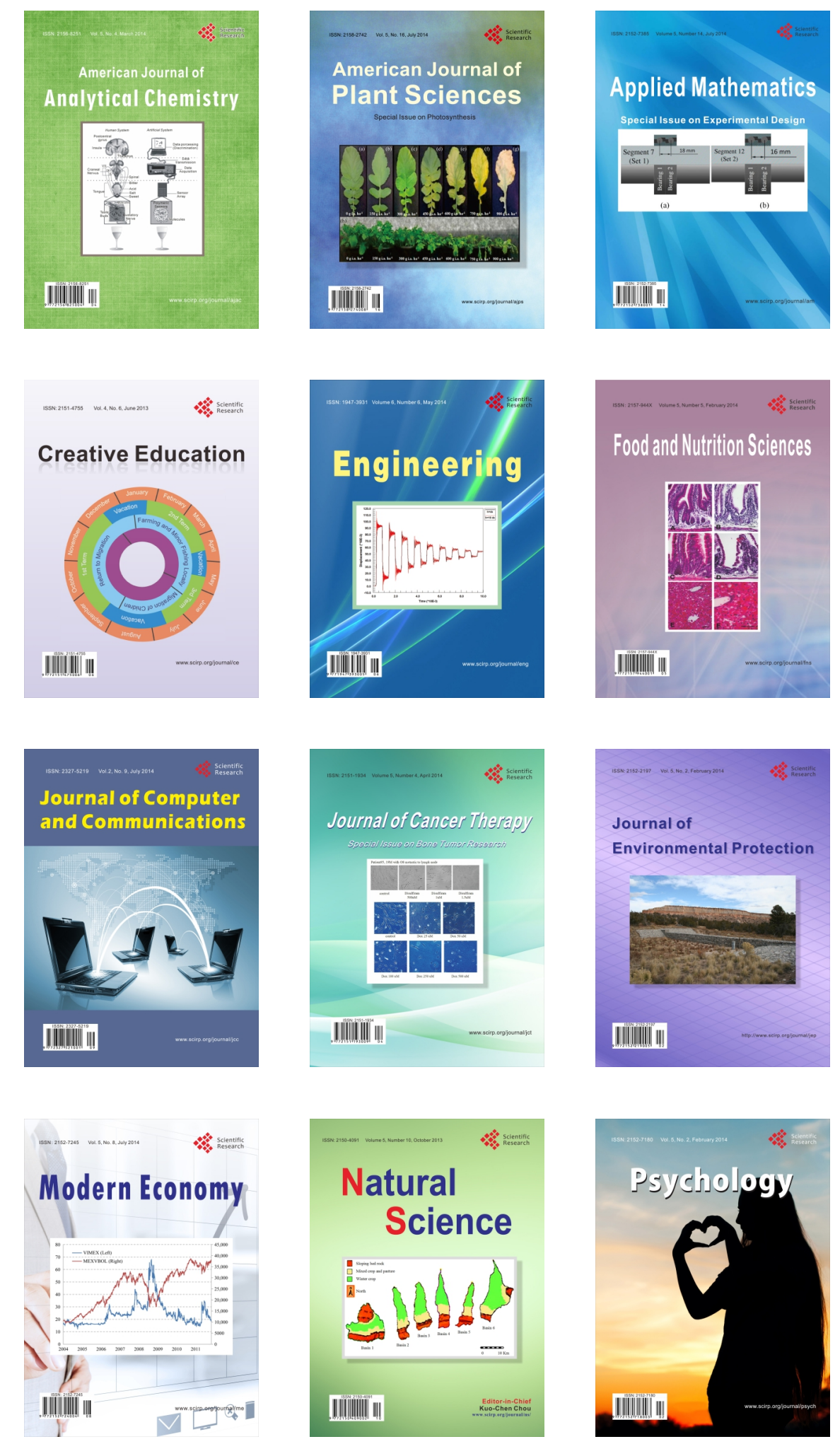